\title{
Insulin Resistance: A Bridge between T2DM and Alzheimer's Disease
}

\author{
Daniela Giacomazza ${ }^{1}$ and Marta Di Carlo*
}

${ }^{1}$ ConsiglioNazionaledelleRicerche-Istituto di Biofisica, Italy

${ }^{2}$ ConsiglioNazionaledelleRicerche-Istituto di Biomedicina e ImmunologiaMolecolare, Italy

Type 2 diabetes mellitus (T2DM) is a metabolic disorder in which insulin is no longer able to control the levels of blood sugar.A westernstyle diet in combination with the lack of exercise is the mainfactor for the increase of T2DM. While in the past people onlydeveloped T2DM at older age ("old age diabetes"), now even teenagerscontract T2DMbecause of the change in the lifestyle. Western diet is characterized by the exponential increase in the consumption of highly treated foods without appropriate nutrients for systemic metabolic functions or with added ingredients that prejudice protective actions of natural food constituent.

T2DM is caused by insulin resistance in the tissues, no longer able to respond to the hormone action. It is most frequently associated with aging, a family history of diabetes, obesity, and failure of exercise.The insulin, ahormone produced by the beta-cells of the pancreas, is the key biomolecule for the regulation of carbohydrate and lipid metabolism. Although its action in body organs mainly concerns the glucose homeostasis, in Central Nervous System insulin performs several functions such as regulation of glucose metabolism, food intake and body weight, fertility and reproduction [1] and others not yet completely known. In particular, the high density of insulin receptors in the hippocampus and cerebral cortex regions has suggested its participation in learning and memory process. The administration of insulin to both humans and animal models has induced an enhancement of the memory function [2] and the treatment with insulin has given in several animal models beneficial effects to prevent memory loss after ischemia episodes whereas no effects are observed with glucose alone [3]. Insulin is also involved in the synaptic plasticity, for example, it as been show that insulin allows the long-lasting enhancement of GABA receptormediated synaptic transmission [4] and promote the internalization of AMPA receptors from the neuron synaptic membrane causing a long-term depression (LTD) of excitatory synaptic transmission in the hippocampus and cerebellum $[5,6]$. LTD is a process that, together with the opposite one, long-term potentiation has a great relevance for brain information storage and improvement of neurons links during development [7]. Furthermore, insulin receptor signaling regulates the maintenance of synapses and contributes to experience-dependent structural plasticity that is necessary for the recruitment of neurons into brain circuits [8]. Moreover, some studies suggest that insulin participates in neuronal differentiation of postnatal neural stem cell [9] and their culturing with both insulin and insulin-like growth factor (GF-1) causes a greater production of neurons during differentiation compared to culturesstimulated by IGF-1 alone [10].

Insulin also avoids the necrosis of rat embryonic neurons cultured in a serum-free medium; in fact the protein was capable to restore the cell viability by activation of Protein Kinase C, having the crucial role of controlling other proteins through the phosphorylation of their serine and threonine amino acid residues; on the contrary, insulinlike growth factor addition had no effect [11]. Clearly, in the insulin resistance state, these functions are impaired.

On the basis of the large number of observations, since the first years of the XXI century, T2DM has been identified as a risk factor for Alzheimer's disease (AD) [12-17]. Epidemiological studies of patient groups have evidenced a clear correlation between T2DMand the probability of developing $\mathrm{AD}$ or other neurodegenerative disorders [18]. AD, the most common form of dementia in the elderly is clinically characterized by gradual worsening of the symptoms. AD patients have, at the initial stage of the pathology, mild memory loss, difficulty performing routine tasks, trouble communicating and understanding written material. At the final stage of the disease they loose the ability to feed themselves, speak, recognize people and a constant care is typically necessary. At macroscopic level AD destroys nerve tissues in all parts of the brain causing a dramatically shrunk brain thus affecting almost all functions. The contraction is severe especially in the hippocampus, a region responsible for working memory as well as the formulation of new memories. Other conspicuous brain lesions in AD include the contraction of the cortex, causing the damage of regions responsible for thinking, remembering and planning.At microscopic level AD is characterized by neuronal cell loss and increasing deposition of neurofibrillary tangles (NTF) inside the cells and formation of amyloid plaques in the spaces among neurons and in the walls of blood vessels [19]. NTF are insoluble twisted fibers consisting primarily of the Tau protein, which, in physiological conditions, helps to stabilize the microtubules, promoting the assembly. In $\mathrm{AD}$, however, Tau is abnormally phosphorylated and this results in the collapse of transport system and malfunction in communication between neuronal cells. This finding supports the hypothesis that the chemical modification of tau could be a triggering event in $\mathrm{AD}$ pathology. In addition to phosphorylation, Tau undergoes many post-translationalmodifications, supposed to be involved in its pathological assembly [20,21]. In the last decade, the interest of researchers has been focused on the action of O-linked $\mathrm{N}$-acetylglucosamine promoting the glycosylation of Tau serine and threonine residues (O-GlcNAc). O-GlcNAc can compete with phosphorylation at specific sites of several proteins, including Tau thus inhibiting its phosphorylation and aggregation. Its removal is operated by a glycoside hydrolase (OGA) and the treatment of cells [22], tissue ex vivo [23] and rats [24] with OGA inhibitors has induced a reduction Tau phosphorylation at crucial pathological sites. Being O-GlcNAc synthetized starting from glucose, it is strongly dependent on glucose concentration and it has been evidenced that the reduction of glucose availability correlates with a decrease of O-GlcNAc and an increase of phosphorylated Tau $[25,26]$.

Amyloid plaques are mainly composed by the amyloid beta peptide (Abeta), a 39-to-43 peptide due to the sequential cleavage of the larger

*Corresponding author: Marta Di Carlo, ConsiglioNazionaledelleRicerche-Instituto di Biomedicina e ImmunologiaMolecolare, Via U. La Malfa 153-90146 Palermo, Italy, Tel: +39.0916809538; Fax: +39.09168093544; E-mail: di-carlo@ibim.cnr.it

Received March 14, 2013; Accepted April 29, 2013; Published May 05, 2013

Citation: Giacomazza D, Di Carlo M (2013) Insulin Resistance: A Bridge between T2DM and Alzheimer's Disease. J Diabetes Metab 4: 263. doi:10.4172/21556156.1000263

Copyright: $\odot 2013$ Giacomazza D, et al. This is an open-access article distributed under the terms of the Creative Commons Attribution License, which permits unrestricted use, distribution, and reproduction in any medium, provided the original author and source are credited. 
trans-membrane protein called Amyloid Precursor Protein (APP). Accumulation of Abeta is hypothesized to trigger the pathogenic cascade leading to $\mathrm{AD}$ [27] and in the last decade, many observations confirm that small oligomers, also called Abeta-derived diffusible ligands (ADDLs), instead of large fibril aggregates, are the most dangerous and toxic species in $\mathrm{AD}$ onset $[28,29]$. Their accumulation and binding in the proximity of synapses cause oxidative stress, loss of spines and receptors, critical for neuron plasticity and memory [30].

Some studies have suggested that the main link between T2DM and $\mathrm{AD}$ is the disorder in insulin signaling and it was found that plasma Abeta $_{1-40}$ and Abeta $_{1-42}$ levels are increased in patients with hyperglycemia [31-33] and also, Abeta impairs insulin signaling in mouse liver and cultured hepatocytes by activating JAK2/STAT3/ SOCS-1 signaling pathway [31]. Furthermore the injection of anti Abeta-neutralizing antibodies in APPswe/PSEN1dE9 AD model mice causes decreased fasting blood glucose level and improved insulin sensitivity [31]. By examining postmortem brain tissues of AD patients at different stages, it was found that $\mathrm{AD}$ might be a neuroendocrine disease associated with insulin signaling. It was investigated if the neurodegeneration was associated with significant abnormalities in the expression of genes encoding insulin, Insulin-like Growth Factor (IGF)-1 and -2 peptides, their receptors, and downstream signaling mechanisms. In these cases insulin, IGF-1 and IGF-2 polypeptides expression was inversely proportional to the Braak stage (a method used to classify the degree of $\mathrm{AD}$ ), with a relevant decrease in the number of insulin receptors (IR) in AD patients compared to normal subjects. In addition, the ability of insulin to bind the receptors was compromised. The authors of this studyproposed that $\mathrm{AD}$ can be regarded as a brain-specific form of diabetes and referred it to as "type 3 diabetes" (T3D) because it presents characteristic of diabetes 1 and 2 , since insulin resistance and insulin deficiency coexist [34,35]. Thus, the impairments in cerebral glucose utilization and energy metabolism represent abnormalities that accompany the different stages of cognitive impairment and neurodegenerationin $\mathrm{AD}$. This is in agreement with the fact that insulin/IGF signaling regulates neuronal growth, survival, energy metabolism and plasticity, which are required for learning and memory [36].

Obesity, another health problem of the western countries, is also considered a risk factor for $\mathrm{AD}$ onset and obese animal models have manifested reduced insulin sensitivity before the development of T2DM [37,38]. The disproportionate assumption of saturated fats besides inducing serious and already known cardiovascular damages is also associated with T2DM insurgence and neuronal and/or myelin abnormalities, which may in turn accelerate aging and subsequently the development of age-related cognitive impairment.In terms of brain function, obesity may disturb cognition and executive functions in obese when compared to normal-weight people [39-41]

Experimental animal models have complemented the human postmortem studies indicating once more the strict connection between insulin and AD.Sporadic AD wasinducedin animal model by intracerebral injection of streptozotocin (STZ), a pro-diabetic drug, in pup rats, having normal blood glucose levelsand pancreatic morphology similar to control. The treated rats developed cognitive impairment with deficits in spatial learning and memory. Their brainswere reduced in size and exhibited the same alterations observable in $\mathrm{AD}$ brain [42].

Some factors as impaired glucose utilization, oxidative stress mitochondrial dysfunction, reduced energy metabolism and ATP production, cause or contribute to $\mathrm{AD}$ pathogenesis and this seems to be mediated by desensitization of the neuronal insulin receptor.
Insulin can protect cultured rat neurons against Abeta induced toxicity [43] and experimental data have demonstrated that soluble Abeta fragments directly bind to and decrease insulin receptor densities on neuronal dendrites [44]. This results in a decrease in autophosphorylation of the insulin receptor suggesting that it may be a mechanism by which insulin signaling in the brain becomes impaired in $\mathrm{AD}$ people.

Other studies indicate that insulin, interacting with Abeta, inhibits its fibrillar growth as shown in a cell-free assay and in the cell surface of human brain pericytes reducing the Abeta toxic effect [45]. Recently, it has been proposed that physiological insulin and pathological ADDLs are capable to regulate their mutual binding site abundance, creating a competitive balance between synapse survival and degeneration. The decline of the insulin signaling in the brain with the age displaces this delicate equilibrium in favor of the ADDLs [30]; thus, the use of new drugs recovering this balance could be a promising therapeutic strategy.

Based on these results, what is the effect of insulin on Abeta toxicity at the molecular level? In other words the question is: if the impaired insulin signaling contributes to the pathogenesis of $\mathrm{AD}$, can the administration of insulin or, better, the improvements of insulin sensitivity be considered potential therapeutic strategies against the disease?

Experimental data have established that Abeta toxicity causes insulin resistance and insulin resistance, with associated oxidative stress and inflammation, promotes, in a vicious circle, Abeta accumulation and toxicity [46-48]. Other evidences indicate that insulin can recover the cell viability by inhibition of intrinsic apoptotic program, involving caspase 9 and 3 activation [16]. Moreover, insulin prevents mitochondrial dysfunction by inhibition of the reactive oxygen species (ROS) formation and activationof specific cell signaling. Insulin activates the serine-threonine kinase Akt, a protein involved in survival pathway, suggesting that insulin signaling provides a physiological defense mechanism to contrast the death program triggered by Abeta oligomers [49,50].

Akt phosphorylation needs activation or inhibition of several proteins involved in the apoptotic signaling cascade such as the Bcl-2 protein family. Moreover, insulin promotes the cell survival program shuttling in different sub-cellular compartments [51]. Translocation of Akt from the cytoplasm to the nucleus induces negative regulation of gene expressions via Foxo3a, a pro-apoptotic transcription factor. Akt translocation from the cytoplasm to the mitochondrion mediates, instead, the protection of this organelle through phosphorylation of Bad and probably HK-II, two proteins involved in cell death.Thus, the same molecule, depending on its phosphorylated or un-phosphorylated state, can be present in a particular cellular compartment as nucleus, cytoplasm, mitochondrion and this localization is essential to determine between cell life or death. Hence, a precise balance between signals promoting survival and apoptosis is important for determining cell fate [51]. Because insulin signaling in the brain is known to decline with age the outcome of this balance represents a risk factor for $\mathrm{AD}$ well suited for therapeutic intervention, perhaps with the same insulin. In the last few years many attempts have been done to slow or stop the $\mathrm{AD}$ progression with the aid of insulin but the usual method used to treat diabetes could be very dangerous for $\mathrm{AD}$ patients and for this reason alternative routes of administration have been explored.

The intranasal administration of insulin, already tested for diabetes treatment [52], to AD patients has improved delayed memory and 
changes in memory and function were associated with changes in the Abeta $_{1-42}$ level and in the Tau protein-to-A-beta ${ }_{42}$ ratio in cerebrospinal fluid $[53,54]$. This employment of insulin appeared a good strategy because intranasal administration leads to direct access of insulin into the brain along the olfactory nerves thus being able to exert a selective cerebral or neuronal action without its systemic effects on glycemic levels. Unfortunately, together with positive effects this method presents contraindications such as irritation and damage of the nasal mucosa [55] and, surely more important, increase of the systolic, diastolic and arterial blood pressures [56].

The hormonal therapy has shown positive effects also in the case of Glucagon-like peptide-1 (GLP-1) and its natural degradation product $1_{(9-36) \text { (Amide) }}$ GLP-1 is an incretin hormone secreted by enteroendocrine cells that causes an increase of the insulin level even before blood glucose amount becomes elevated. GLP-1 plays an important role by stimulating insulin secretion, inhibiting glucagon production, and improving beta-cell function in type-2 diabetes mellitus (T2DM) and insulin resistance models $[57,58]$.

GPL-1 has a short lifetime and is quickly cleaved into the shorter form GLP-1 $1_{(9-36)(\text { Amide) }}[59]$. Recent studies have demonstrated that this degradation product, initially considered inactive, has important physiological roles [60], different from those of its precursor. In fact, GLP-1 ${ }_{(9-36)(\text { Amide) }}$ treatment, besides preventing mitochondrial superoxide production induced by high glucose or fatty acid levels, improves the loss of memory and synaptic plasticity associated with $\mathrm{AD}$ in model mouse [61], thus suggesting suitable therapeutic approach.

In summary, aging is the most significant risk factor for T2DM and especially for $\mathrm{AD}$ and both pathologies share insulin resistance and impaired energy metabolism indicating that both can be considered as metabolic diseasesthus opening the door to common and/or complementary diagnostic and therapeutic approaches. On these results, it is possible that lifestyle modifications, diet, microand macro-nutrients supplements, and consumption of natural food substancesrichesin antioxidants, from early age, supported from aerobic exercise could prevent, retard or cure these diseases.

\section{References}

1. Wickelgren I (1998) Tracking insulin to the mind. Science 280: 517-519.

2. Park CR, Seeley RJ, Craft S, Woods SC (2000) Intracerebroventricular insulin enhances memory in a passive-avoidance task. Physiol Behav 68: 509-514

3. Voll CL, Auer RN (1991) Insulin attenuates ischemic brain damage independent of its hypoglycemic effect. J Cereb Blood Flow Metab 11: 1006-1014.

4. Wan Q, Xiong ZG, Man HY, Ackerley CA, Braunton J, et al. (1997) Recruitment of functional GABAA receptors to post-synaptic domains by insulin. Nature 388 : 686-690

5. Huang CC, You JL, Lee CC, Hsu KS (2003) Insulin induces a novel form of postsynaptic mossy fiber long-term depression in the hippocampus. Mol Cell Neurosci 24: 831-841.

6. Huang CC, Lee CC, Hsu KS (2004) An investigation into signal transduction mechanisms involved in insulin-induced long-term depression in the CA1 region of the hippocampus. J Neurochem 89: 217-231.

7. Siegelbaum SA, Kandel ER (1991) Learning-related synaptic plasticity: LTP and LTD. Curr Opin Neurobiol 1: 113-120.

8. Chiu SL, Chen CM, Cline HT (2008) Insulin receptor signaling regulates synapse number, dendritic plasticity, and circuit function in vivo. Neuron 58: 708-719.

9. Han J, Wang B, Xiao Z, Gao Y, Zhao Y, et al. (2008) Mammalian target of rapamycin (mTOR) is involved in the neuronal differentiation of neural progenitors induced by insulin. Mol Cell Neurosci 39: 118-124.
10. Arsenijevic $Y$, Weiss $S$ (1998) Insulin-like growth factor-I is a differentiation facto for postmitotic CNS stem cell-derived neuronal precursors: distinct actions from those of brain-derived neurotrophic factor. J Neurosci 18: 2118-2128.

11. Hamabe W, Fujita R, Ueda $H$ (2003) Neuronal necrosis inhibition by insulin through protein kinase C activation. J Pharmacol Exp Ther 307: 205-212.

12. Rönnemaa E, Zethelius B, Sundelöf J, Sundström J, Degerman-Gunnarsson $M$, et al. (2008) Impaired insulin secretion increases the risk of Alzheimer disease. Neurology 71: 1065-1071.

13. Hoyer S (2002) The brain insulin signal transduction system and sporadic (type II) Alzheimer disease: an update. J Neural Transm 109: 341-360.

14. Hoyer S (2004) Causes and consequences of disturbances of cerebral glucose metabolism in sporadic Alzheimer disease: therapeutic implications. Adv Exp Med Biol 541: 135-152

15. Rivera EJ, Goldin A, Fulmer N, Tavares R, Wands JR, et al. (2005) Insulin and insulin-like growth factor expression and function deteriorate with progression of Alzheimer's disease: link to brain reductions in acetylcholine. J Alzheimers Dis 8: $247-268$.

16. Di Carlo M, Picone P, Carrotta R, Giacomazza D, San Biagio PL (2010) Insulin promotes survival of amyloid-beta oligomers neuroblastoma damaged cells via caspase 9 inhibition and Hsp70 upregulation. J Biomed Biotechnol 2010 147835

17. Neumann KF, Rojo L, Navarrete LP, Farías G, Reyes P, et al. (2008) Insulin resistance and Alzheimer's disease: molecular links \& clinical implications. Cur Alzheimer Res 5: 438-447.

18. Haan MN (2006) Therapy Insight: type 2 diabetes mellitus and the risk of lateonset Alzheimer's disease. Nat Clin Pract Neurol 2: 159-166.

19. Wisniewski HM, Frackowiak J (1998) Commentary to: Differences between the pathogenesis of senile plaques and congophilic angiopathy in Alzheimer disease. (J Neuropathol Exp Neurol 1997; 56:751-61) J Neuropathol Exp Neurol 57: 96-98.

20. Gong CX, Liu F, Grundke-lqbal I, Iqbal K (2005) Post-translational modifications of tau protein in Alzheimer's disease. J Neural Transm 112: 813-838.

21. Marcus JN, Schachter J (2011) Targeting post-translational modifications on tau as a therapeutic strategy for Alzheimer's disease. J Neurogenet 25: 127-133.

22. Lefebvre T, Ferreira S, Dupont-Wallois L, Bussière T, Dupire MJ, et al. (2003) Evidence of a balance between phosphorylation and O-GIcNAc glycosylation of Tau proteins--a role in nuclear localization. Biochim Biophys Acta 1619: 167176

23. Liu F, Iqbal K, Grundke-lqbal I, Hart GW, Gong CX (2004) O-GlcNAcylation regulates phosphorylation of tau: a mechanism involved in Alzheimer's disease. Proc Natl Acad Sci U S A 101: 10804-10809.

24. Yuzwa SA, Macauley MS, Heinonen JE, Shan X, Dennis RJ, et al. (2008) A potent mechanism-inspired O-GIcNAcase inhibitor that blocks phosphorylation of tau in vivo. Nat Chem Biol 4: 483-490.

25. Li X, Lu F, Wang JZ, Gong CX (2006) Concurrent alterations of O-GIcNAcylation and phosphorylation of tau in mouse brains during fasting. Eur J Neurosci 23 2078-2086.

26. Liu F, Shi J, Tanimukai H, Gu J, Gu J, et al. (2009) Reduced O-GlcNAcylation links lower brain glucose metabolism and tau pathology in Alzheimer's disease. Brain 132: 1820-1832.

27. Hardy J, Allsop D (1991) Amyloid deposition as the central event in the aetiology of Alzheimer's disease. Trends Pharmacol Sci 12: 383-388.

28. Lambert MP, Barlow AK, Chromy BA, Edwards C, Freed R, et al. (1998) Diffusible, nonfibrillar ligands derived from $A$ beta1-42 are potent central nervous system neurotoxins. Proc Natl Acad Sci U S A 95: 6448-6453.

29. Picone P, Carrotta R, Montana G, Nobile MR, San Biagio PL, et al. (2009) Abeta oligomers and fibrillar aggregates induce different apoptotic pathways in LAN5 neuroblastoma cell cultures. Biophys J 96: 4200-4211.

30. De Felice FG, Vieira MN, Bomfim TR, Decker H, Velasco PT, et al. (2009) Protection of synapses against Alzheimer's-linked toxins: insulin signaling prevents the pathogenic binding of Abeta oligomers. Proc Natl Acad Sci U S A 106: 1971-1976. 
Citation: Giacomazza D, Di Carlo M (2013) Insulin Resistance: A Bridge between T2DM and Alzheimer's Disease. J Diabetes Metab 4: 263. doi:10.4172/2155-6156.1000263

31. Zhang Y, Zhou B, Zhang F, Wu J, Hu Y, et al. (2012) Amyloid-Î ${ }^{2}$ induces hepatic insulin resistance by activating JAK2/STAT3/SOCS-1 signaling pathway. Diabetes 61: 1434-1443.

32. Zhang Y, Zhou B, Deng B, Zhang F, Wu J, et al. (2013) Amyloid-î́2 induces hepatic insulin resistance in vivo via JAK2. Diabetes 62: 1159-1166.

33. Sato N, Morishita R (2013) Plasma aî2: a possible missing link between Alzheimer disease and diabetes. Diabetes 62: 1005-1006.

34. Steen E, Terry BM, Rivera EJ, Cannon JL, Neely TR, et al. (2005) Impaired insulin and insulin-like growth factor expression and signaling mechanisms in Alzheimer's disease--is this type 3 diabetes? J Alzheimers Dis 7: 63-80.

35. de la Monte SM, Wands JR (2005) Review of insulin and insulin-like growth factor expression, signaling, and malfunction in the central nervous system: relevance to Alzheimer's disease. J Alzheimers Dis 7: 45-61.

36. D'Ercole AJ, Ye P, Calikoglu AS, Gutierrez-Ospina G (1996) The role of the insulin-like growth factors in the central nervous system. Mol Neurobiol 13: 227 255.

37. Shulman GI (2000) Cellular mechanisms of insulin resistance. J Clin Invest 106: 171-176.

38. Carvalheira JB, Ribeiro EB, Araújo EP, Guimarães RB, Telles MM, et al. (2003) Selective impairment of insulin signalling in the hypothalamus of obese Zucker rats. Diabetologia 46: 1629-1640.

39. Elias MF, Elias PK, Sullivan LM, Wolf PA, D'Agostino RB (2003) Lower cognitive function in the presence of obesity and hypertension: the Framingham heart study. Int J Obes Relat Metab Disord 27: 260-268.

40. Elias MF, Elias PK, Sullivan LM, Wolf PA, D’Agostino RB (2005) Obesity, diabetes and cognitive deficit: The Framingham Heart Study. Neurobiol Aging 26 Suppl 1: 11-16.

41. Waldstein SR, Katzel LI (2006) Interactive relations of central versus total obesity and blood pressure to cognitive function. Int J Obes (Lond) 30: 201-207.

42. Lester-Coll N, Rivera EJ, Soscia SJ, Doiron K, Wands JR, et al. (2006) Intracerebral streptozotocin model of type 3 diabetes: relevance to sporadic Alzheimer's disease. J Alzheimers Dis 9: 13-33.

43. Zhao WQ, De Felice FG, Fernandez S, Chen H, Lambert MP, et al. (2008) Amyloid beta oligomers induce impairment of neuronal insulin receptors. FASEB J 22: 246-260.

44. Carrotta R, Di Carlo M, Manno M, Montana G, Picone P, et al. (2006) Toxicity of recombinant beta-amyloid prefibrillar oligomers on the morphogenesis of the sea urchin Paracentrotus lividus. FASEB J 20: 1916-1917.

45. Rensink AA, Otte-Höller I, de Boer R, Bosch RR, ten Donkelaar HJ, et al (2004) Insulin inhibits amyloid beta-induced cell death in cultured human brain pericytes. Neurobiol Aging 25: 93-103.

46. Watson GS, Peskind ER, Asthana S, Purganan K, Wait C, et al. (2003) Insulin increases CSF Abeta42 levels in normal older adults. Neurology 60: 18991903.

47. Gasparini L, Gouras GK, Wang R, Gross RS, Beal MF, et al. (2001) Stimulation of beta-amyloid precursor protein trafficking by insulin reduces intraneuronal beta-amyloid and requires mitogen-activated protein kinase signaling. $J$ Neurosci 21: 2561-2570.

48. Messier C, Teutenberg K (2005) The role of insulin, insulin growth factor, and insulin-degrading enzyme in brain aging and Alzheimer's disease. Neural Plast 12: $311-328$

49. Song G, Ouyang G, Bao S (2005) The activation of Akt/PKB signaling pathway and cell survival. J Cell Mol Med 9: 59-71.

50. Lee HK, Kumar P, Fu Q, Rosen KM, Querfurth HW (2009) The insulin/Ak signaling pathway is targeted by intracellular beta-amyloid. Mol Biol Cell 20: 1533-1544.

51. Picone P, Giacomazza D, Vetri V, Carrotta R, Militello V, et al. (2011) Insulin- activated Akt rescues $A \hat{I}^{2}$ oxidative stress-induced cell death by orchestrating molecular trafficking. Aging Cell 10: 832-843.

52. Lalej-Bennis D, Boillot J, Bardin C, Zirinis P, Coste A, et al. (2001) Efficacy and tolerance of intranasal insulin administered during 4 months in severely hyperglycaemic Type 2 diabetic patients with oral drug failure: a cross-over study. Diabet Med 18: 614-618.

53. Reger MA, Watson GS, Green PS, Baker LD, Cholerton B, et al. (2008) Intranasal insulin administration dose-dependently modulates verbal memory and plasma amyloid-beta in memory-impaired older adults. J Alzheimers Dis 13: 323-331.

54. Craft S, Baker LD, Montine TJ, Minoshima S, Watson GS, et al. (2012) Intranasal insulin therapy for Alzheimer disease and amnestic mild cognitive impairment: a pilot clinical trial. Arch Neurol 69: 29-38.

55. Nolte MS, Taboga C, Salamon E, Moses A, Longenecker J, et al. (1990) Biological activity of nasally administered insulin in normal subjects. Horm Metab Res 22: 170-174.

56. Cernea S, Raz I (2006) Noninjectable methods of insulin administration. Drugs Today (Barc) 42: 405-424.

57. Gault VA, Hölscher C (2008) GLP-1 agonists facilitate hippocampal LTP and reverse the impairment of LTP induced by beta-amyloid. Eur J Pharmacol 587 112-117.

58. McClean PL, Gault VA, Harriott P, Hölscher C (2010) Glucagon-like peptide-1 analogues enhance synaptic plasticity in the brain: a link between diabetes and Alzheimer's disease. Eur J Pharmacol 630: 158-162.

59. Baggio LL, Drucker DJ (2007) Biology of incretins: GLP-1 and GIP. Gastroenterology 132: 2131-2157.

60. Tomas E, Stanojevic V, Habener JF (2011) GLP-1-derived nonapeptide GLP1(28-36)amide targets to mitochondria and suppresses glucose production and oxidative stress in isolated mouse hepatocytes. Regul Pept 167: 177-184.

61. Ma T, Du X, Pick JE, Sui G, Brownlee M, et al. (2012) Glucagon-like peptide-1 cleavage product GLP-1(9-36) amide rescues synaptic plasticity and memory deficits in Alzheimer's disease model mice. J Neurosci 32: 13701-13708. 